\title{
Role of Porphyromonas gingivalis gingipains in multi-species biofilm formation
}

\author{
Kai Bao ${ }^{1}$, Georgios N Belibasakis², Thomas Thurnheer², Joseph Aduse-Opoku³, Michael A Curtis ${ }^{3}$ \\ and Nagihan Bostanci ${ }^{i^{*}}$
}

\begin{abstract}
Background: Periodontal diseases are polymicrobial diseases that cause the inflammatory destruction of the tooth-supporting (periodontal) tissues. Their initiation is attributed to the formation of subgingival biofilms that stimulate a cascade of chronic inflammatory reactions by the affected tissue. The Gram-negative anaerobes Porphyromonas gingivalis, Tannerella forsythia and Treponema denticola are commonly found as part of the microbiota of subgingival biofilms, and they are associated with the occurrence and severity of the disease. $P$. gingivalis expresses several virulence factors that may support its survival, regulate its communication with other species in the biofilm, or modulate the inflammatory response of the colonized host tissue. The most prominent of these virulence factors are the gingipains, which are a set of cysteine proteinases (either Arg-specific or Lys-specific). The role of gingipains in the biofilm-forming capacity of $P$. gingivalis is barely investigated. Hence, this in vitro study employed a biofilm model consisting of 10 "subgingival" bacterial species, incorporating either a wild-type $P$. gingivalis strain or its derivative Lys-gingipain and Arg-gingipan isogenic mutants, in order to evaluate quantitative and qualitative changes in biofilm composition.
\end{abstract}

Results: Following $64 \mathrm{~h}$ of biofilm growth, the levels of all 10 species were quantified by fluorescence in situ hybridization or immunofluorescence. The wild-type and the two gingipain-deficient $P$. gingivalis strains exhibited similar growth in their corresponding biofilms. Among the remaining nine species, only the numbers of $T$. forsythia were significantly reduced, and only when the Lys-gingipain mutant was present in the biofilm. When evaluating the structure of the biofilm by confocal laser scanning microscopy, the most prominent observation was a shift in the spatial arrangement of $T$. denticola, in the presence of P. gingivalis Arg-gingipain mutant.

Conclusions: The gingipains of $P$. gingivalis may qualitatively and quantitatively affect composition of polymicrobial biofilms. The present experimental model reveals interdependency between the gingipains of P. gingivalis and T. forsythia or T. denticola.

Keywords: Biofilm, Porphyromonas gingivalis, Gingipains, Tannerella forsythia, Treponema denticola, Periodontal microorganisms, Periodontal disease, Fluorescence in situ hybridization, Immunofluorescence

\section{Background}

Periodontal infections, or periodontal diseases, are a set of chronic inflammatory diseases that destroy the toothsupporting (periodontal) tissues. They are caused by oral bacterial biofilms attaching on the tooth surface. They have the capacity to trigger a series of inflammatory responses, which may destroy the gingival tissue and the alveolar bone supporting the tooth, if they become

\footnotetext{
* Correspondence: nagihan.bostanci@zzm.uzh.ch

'Oral Translational Research, Institute of Oral Biology, Center of Dental Medicine, University of Zürich, Plattenstrasse 11, 8032 Zürich, Switzerland Full list of author information is available at the end of the article
}

exacerbated [1,2]. With regards to its capacity as an ecological niche, the oral cavity can be colonized by more than 700 species [3] and approximately 500 of those can be present within the forming biofilms $[4,5]$. Among the biofilm-associated microbiota, earlier clinical epidemiological studies have demonstrated that three species in particular, also designated as the "red complex", are more associated with periodontal disease than others. These are namely Porphyromonas gingivalis, Tannerella forsythia, and Treponema denticola. They are all Gramnegative anaerobes, with a high proteolytic activity [6]. Among these three, $P$. gingivalis holds a prominent role in 
orchestrating the virulence of the biofilm and the consequent tissue inflammatory response, earning itself the characteristics of a "keystone" periodontal pathogen $[7,8]$. $P$. gingivalis expresses several virulence factors, including, fimbriae, LPS, and its cysteine proteases, namely gingipains [9]. These include the arginine-specific proteinases RgpA and $\mathrm{RgpB}$, and the lysine-specific proteinase Kgp, which represent the majority of the cell-surface proteinases of $P$. gingivalis [10]. Clinical studies have demonstrated that periodontal infection associated with $P$. gingivalis can result in significantly elevated systemic antibody response to the gingipains $[11,12]$.

When growing in a subgingival (below the gingival margin) biofilm under strict anaerobic conditions, $P$. gingivalis is highly dependent on its gingipains for utilizing free amino acids as a source of carbon and nitrogen [13]. Moreover, unlike other gram-negative bacteria, $P$. gingivalis does not produce siderophores to sequester and transport iron but its gingipains mediate the uptake of iron from hemoglobin, heme proteins, and ferritin $[14,15]$. Gingipains are also considered important in the capacity of $P$. gingivalis to evade host defences, by degrading antibacterial peptides, such as neutrophil-derived $\alpha$-defensins, complement factor, such as $\mathrm{C} 3$ and $\mathrm{C} 4$, T cell receptors, such as CD4 and CD8 [16]. Alternatively, P. gingivalis and its gingipains can subvert the host immune response by proactively manipulating host molecules, particularly of the complement $[17,18]$. For instance, $P$. gingivalis may perturb the crosstalk between $\mathrm{C} 5 \mathrm{a}$ receptor and toll-like receptor signalling in order to prevent bacterial clearance and cause dysbiosis [19], eventually resulting in periodontal bone loss [20,21]. The construction and phenotypic analysis of isogenic protease mutants of $P$. gingivalis have confirmed putative functions for these proteolytic enzymes [22]. In vivo studies using the $P$. gingivalis mutant strains in animal models have reinforced the view that the gingipains can modulate the infection process [23-26]. In vitro studies have demonstrated an involvement of the gingipains in the regulation of inflammatory mediators from various host cells, including IL-1 $\alpha$, IL-1 $\beta$, IL-18 [27], receptor activator of NF- $\mathrm{KB}$ ligand (RANKL) [28-31], tumor necrosis factor- $\alpha$ converting enzyme (TACE) [32], protease-activated receptor (PAR)-2 [33], or soluble triggering receptor expressed on myeloid cells (sTREM)-1 [34].

Understanding how different organisms act within a given polymicrobial biofilm brings us closer to understanding the etiological mechanisms of periodontal disease [1]. That is because interactions among different bacterial cells can determine the structural characteristics, maturation and virulence of the biofilms [35-37]. These interactions can occur at several levels, including physical contact, metabolic exchange, and signal-mediated communications [38]. Additionally, species-specific virulence factors may regulate bacterial growth, hence altering the conditions of the ecological niche for biofilm formation. In this respect, most studies involving gingpains have focused on $P$. gingivalis as a single species, which might overlook the bacterial interactions within a complex biofilm community. Therefore, the present study used a 10-species "subgingival" biofilm, aiming to investigate the role of gingipains on the growth and structure of the biofilm, by incorporating $P$. gingivalis gingipain-deficient strains.

\section{Results}

\section{Quantitative evaluation of bacteria in the biofilm}

The numbers for each individual species within the different biofilm groups were quantified either by fluorescence in situ hybridization (FISH) or by immunofluorescence (IF). The growth of $P$. gingivalis was not affected depending on whether the wild-type or the gingipain-deficient strains were used. Statistically, compared to the wild-type strain, the $P$. gingivalis gingipain-deficient strains did not cause significant changes in the growth of the remaining nine-biofilm species in the biofilm, with the exception of $T$. forsythia (Figure 1). In particular, the presence of the Lys-gingipain deficient strain K1A caused a significant $(P<0.01)$ reduction of $T$. forsythia cell numbers, compared to the wild-type W50, or the Arg-gingipain-deficient strain E8 (29.9-fold and 38.6-fold, respectively). However, no significant differences in $T$. forsythia numbers were observed between the wild-type W50 and the Arg-gingipain-deficient E8 biofilm groups.

\section{Qualitative evaluation of biofilm structure by confocal microscopy}

Having identified that a dependency exists between the Lys-gingipain and the growth of T. forsythia, we further investigated the structure of the biofilm by means of confocal laser scanning microscopy (CLSM), and evaluated changes in the presence of the $P$. gingivalis gingipaindeficient strains. Firstly, the focus was placed on the structural association or localization between $P$. gingivalis and $T$. forsythia. Within the biofilm structure, $P$. gingivalis appeared in variable size aggregates or clusters of its own species, with no marked differences observed between the wild-type W50 and the gingipain-deficient strains (Figure 2). The distribution pattern of T. forsythia was in more scattered clusters, observed often in the immediate vicinity of $P$. gingivalis clusters, but not strongly intertwining each other (Figure 2). This pattern was observable irrespective of the use of $P$. gingivalis wild-type W50 or the Arg-gingipain deficient strain E8, whereas when the Lys-gingipain deficient strain K1A was included in the biofilm instead, this association was less obvious (Figure 2), presumably due of the low $T$. forsythia numbers.

It was of further interest to investigate the localization of $T$. denticola within the biofilm structure, as the third member of the "red complex" cluster. Interestingly, 


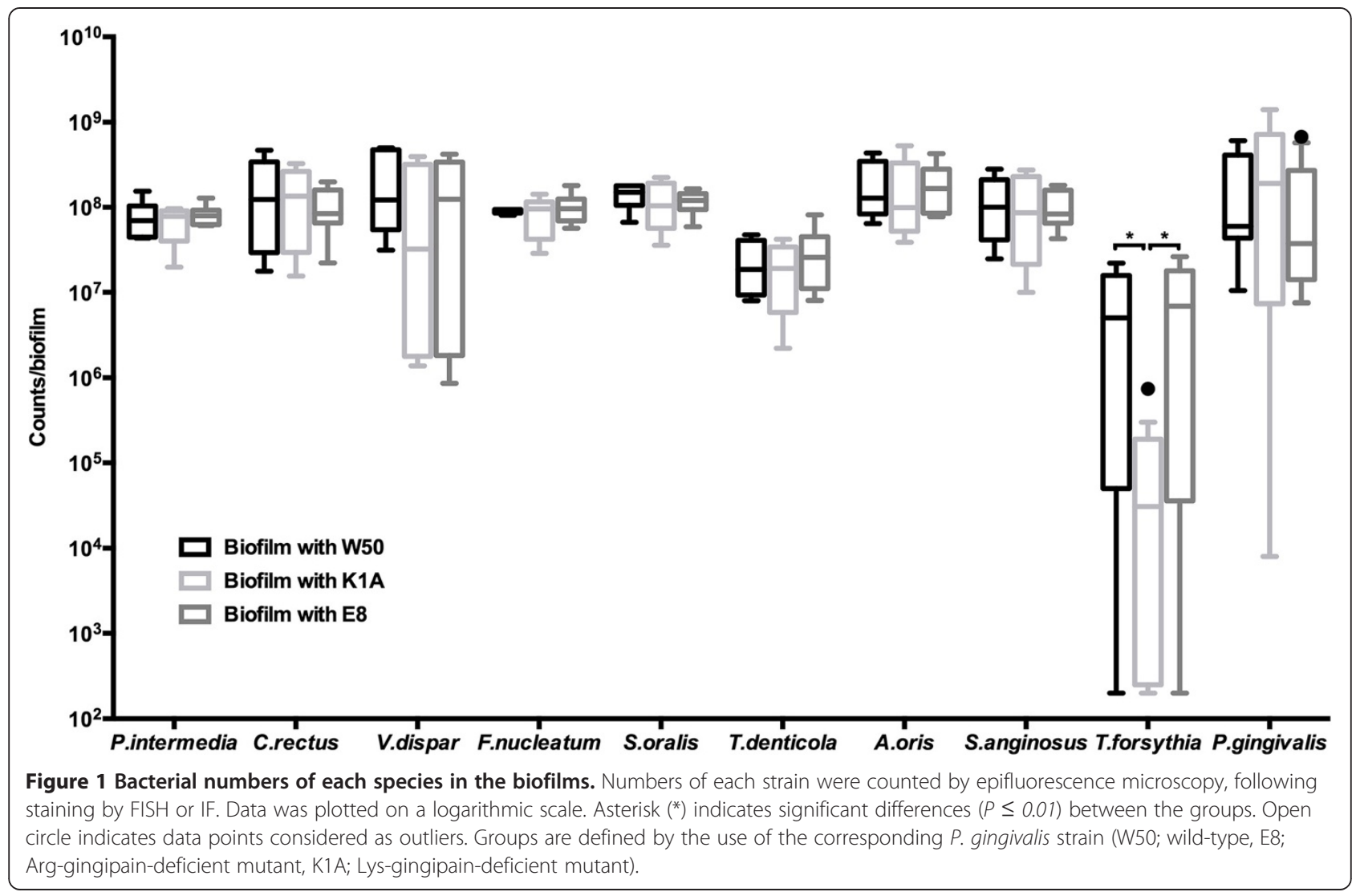

$T$. denticola formed aggregates or clusters in the presence of the $P$. gingivalis wild-type strain W50, as was the case also when the Lys-gingipain deficient strain K1A was used. However, in the presence of the Arg-gingipain deficient strain E8, T. denticola lost this "cluster-like" conformation in the biofilm, and acquired a more even and "thread-like" distribution (Figures 3 and 4). Fusobacterium nucleatum was also strongly present throughout the biofilm and appeared to be evenly distributed among these T. denticola structures (Figure 4).

\section{Discussion}

As it is well established that periodontal diseases are initiated by a mixed-species biofilm [39,40], in vitro biofilm models, may be more accurate in studying the causative factor of the disease, than single species in planktonic

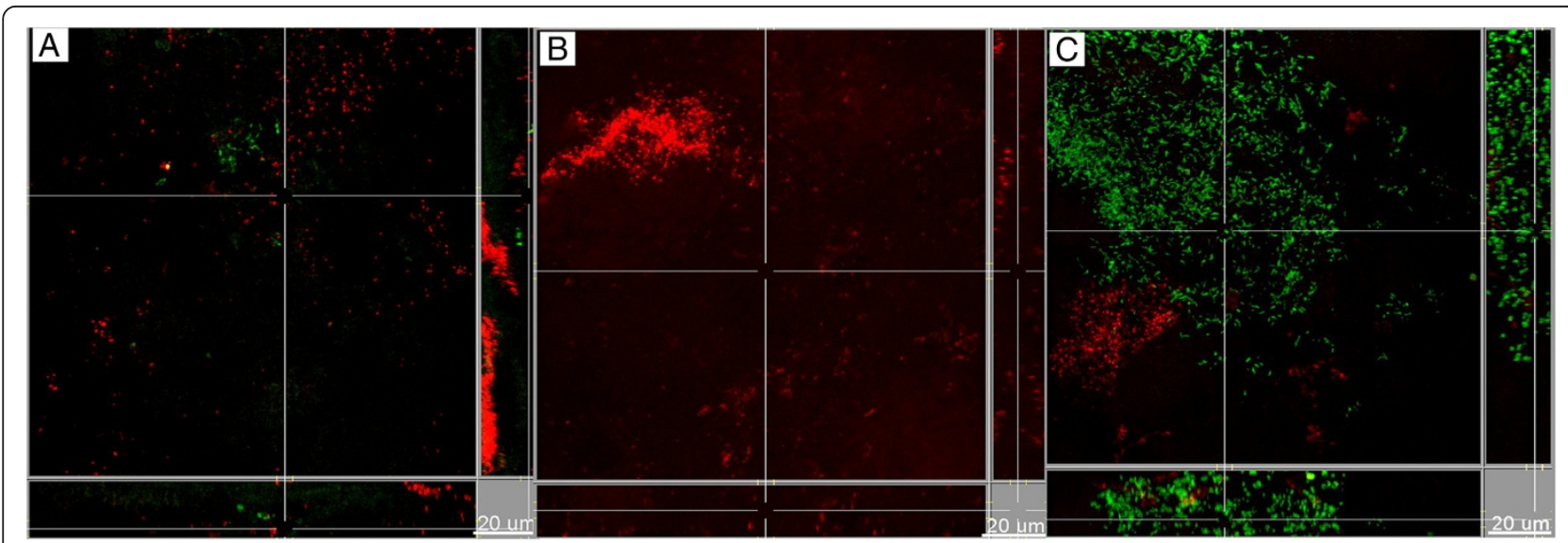

Figure 2 Localization of $P$. gingivalis and T. forsythia within the biofilms. Multiplex IF staining was performed for P. gingivalis (red) and T. forsythia (green). Groups are defined by the use of the (A) wild-type, (B) Arg-gingipain-deficient mutant, (C) Lys-gingipain-deficient mutant P. gingivalis strain in the biofilm. Scale bar length: $20 \mu \mathrm{m}$. 


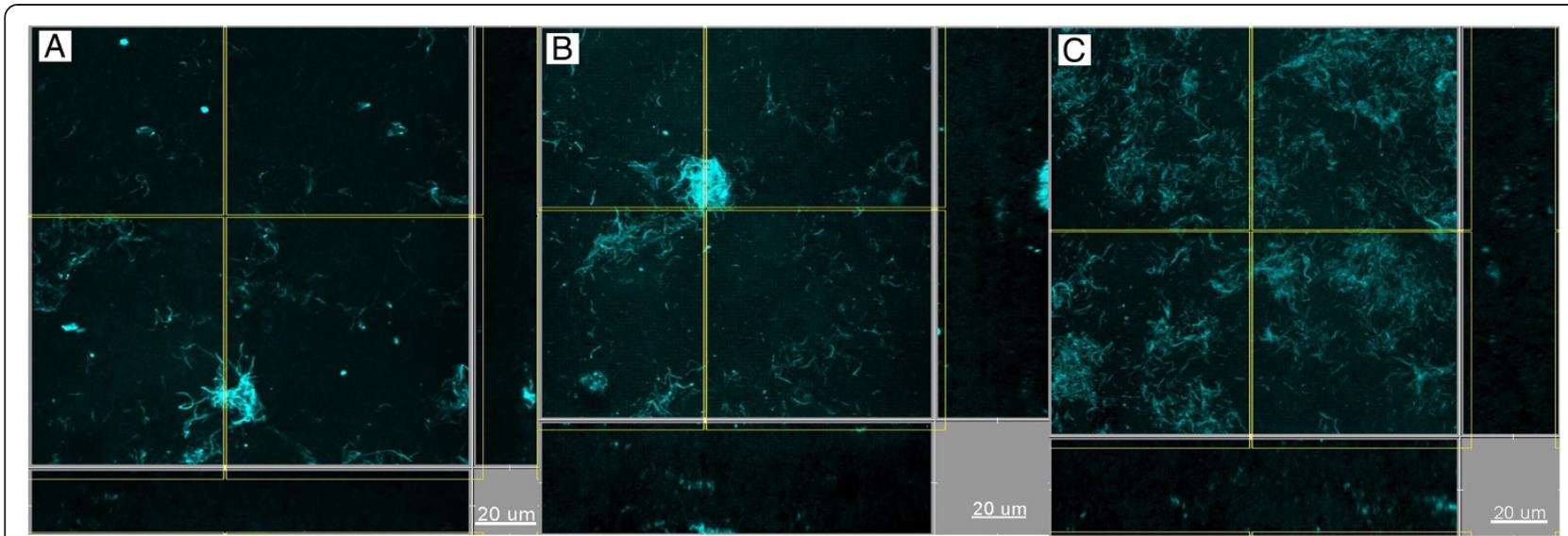

Figure 3 Localization of $T$. denticola within the biofilms. If staining was performed for $T$. denticola (cyan). Groups are defined by the use of the (A) wild-type, (B) Arg-gingipaindeficient mutant, (C) Lys-gingipain-deficient mutant, P. gingivalis strain in the biofilm. Scale bar length: $20 \mu m$.

form $[37,41,42]$. The present study investigated the involvement of $P$. gingivalis gingipains in the quantitative and qualitative composition of a polymicrobial biofilm consisting of 10 species that are frequently comprising part of the subginvival microbial flora. Among their many properties, gingipains are important for the growth of $P$. gingivalis and as transporters for iron [14]. While in planktonic culture $P$. gingivalis gingipain deficient strains require longer doubling times [43], their incorporation into a polymicrobial biofilm did not yield differences in numbers, compared to the wild-type strain. Hence, the growth characteristics of $P$. gingivalis may differ depending on whether it grows in planktonic or biofilm state. When present in a biofilm, gingipains do not appear to be crucial for the growth of $P$. gingivalis, as shown here. Interestingly, among the remaining nine species in the biofilm, the only one whose growth was affected by the presence of gingipains was $T$. forsythia. In particular, the $P$. gingivalis Lys-gingipain deficient strain resulted in a strong reduction in $T$. forsythia numbers after $64 \mathrm{~h}$ of biofilm growth.

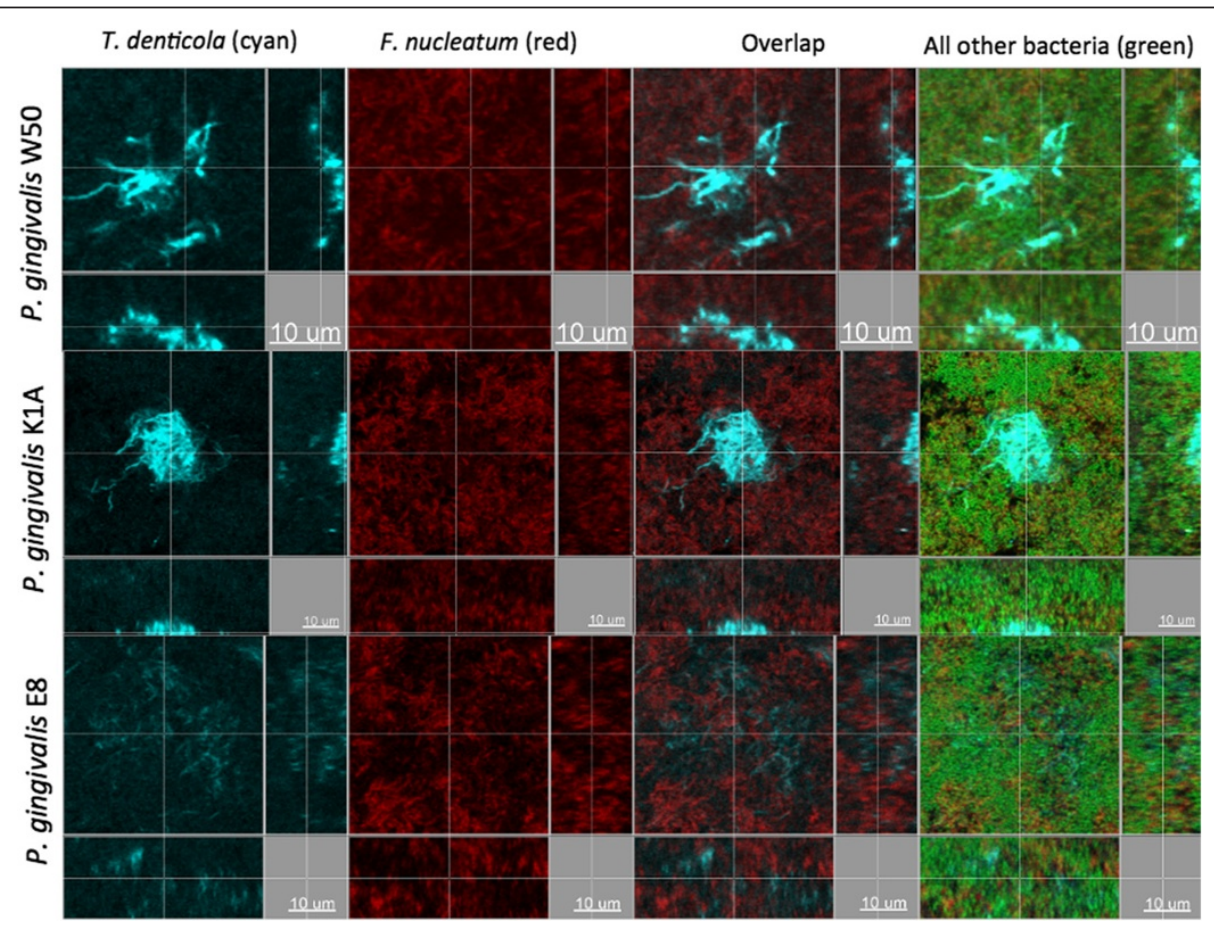

Figure 4 Localization of $P$. gingivalis, F. nucleatum and T. denticola within the biofilms. IF staining was performed for T. denticola (cyan), F. nucleatum (red) and YoPro-1 iodide \& Sytox Green mixture for all other bacteria (green). Groups are defined by the use of the corresponding P. gingivalis strain (W50; wild-type, E8; Arg-gingipain-deficient mutant, K1A; Lys-gingipain-deficient mutant) in the biofilm. Scale bar length: $20 \mu m$. 
Reversely, this indicates that the Lys-gingipain produced by $P$. gingivalis has an additive effect on the growth of $T$. forsythia in the biofilm. This denotes a synergistic association between $T$. forsythia and $P$. gingivalis as mutual components of a polymicrobial community, which is mediated by the Lys-gingipain of the latter.

Previous studies have shown that gingipains are crucial for the co-aggregation of $P$. gingivalis or its co-adhesion with other species, such as $T$. denticola [44-46], or for the invasion of host cells [47]. Hence, the gingipains may not only affect the quantitative composition but also the structural conformation of the biofilm. For this reason, the biofilm architecture was also investigated by CLSM. P. gingivalis occurred in distinguishable and evenly distributed clusters within the biofilm regardless of whether it expressed a gingipain or not. The communities of $T$. forsythia within the biofilm exhibited similar patterns to those of $P$. gingivalis, and were frequently co-localized, yet without impinging onto each other. The proximal association of these two species' communities in biofilm may hint for an ecological relationship. This is also substantiated by the notable absence of $T$. forsythia clusters from the vicinity of the Lys-gingipain deficient $P$. gingivalis. Hence, this gingipain may be important for the growth of $T$. forsythia and its spatial interdependency to $P$. gingivalis within the biofilm. This observation could represent an example of the metabolic responses and bacterial quorum-sensing within the biofilm [48].

Another interesting observation of the present study is that of the structural re-arrangement of $T$. denticola in the biofilm, depending on the presence or absence of the Arg-gingipain. Earlier studies have shown that other species can interact with $P$. gingivalis in both planktonic suspensions and biofilms $[46,49,50]$. A recent study using the similar multi-species biofilm model as here demonstrated that $P$. gingivalis and $T$. denticola have the tendency to co-colonize gingival epithelial tissue [51]. In a dual $P$. gingivalis - T. denticola biofilm, it was also demonstrated that gingipains do contribute to their interaction [50]. In the present experimental model, $T$. denticola cells formed dense circular clumps with the wild-type $P$. gingivalis strain. However, in the presence of the $P$. gingivalis Arg-gingipain deficient strain, this conformation was lost and $T$. denticola cells were instead arranged in looser threaded structures, even though their numbers in the biofilm were not changed. This finding provides further evidence of the ecological association between $P$. gingivalis gingipains and the structural arrangement of $T$. denticola in the biofilm. It is difficult at this stage to interpret the biological meaning of this change in $T$. denticola structure. Of note, in a recent study using the similar biofilm model it was demonstrated that omission of streptococci from the biofilm resulted in numeric changes of $P$. gingivalis and $P$. intermedia. The latter also lost its aggregated form and was arranged in filamentous long chains, resembling those of the missing streptococci [35].

\section{Conclusions}

This study showed that the gingipains of $P$. gingivalis promote quantitative and qualitative shifts in the composition and structure of a multi-species biofilm. More specifically, the Lys-gingipain enhances the growth of T. forsythia, whereas the Arg-gingipain promotes the aggregation of $T$. denticola in the biofilm. These ecological interactions are interpreted as synergistic ones, and may support the survival and the virulence of the biofilm community as a whole.

\section{Methods \\ In vitro biofilm formation}

The method used to develop 10 species biofilm is a modification of a previous report of this model [52], with major changes described below. The following strains were used in this study: Prevotella intermedia ATCC 25611 T (OMZ 278), Campylobacter rectus (OMZ 398), Veillonella dispar ATCC 17748 T (OMZ 493), Fusobacterium nucleatum subsp. nucleatum (OMZ 598), Streptococcus oralis SK248 (OMZ 607), T. denticola ATCC 35405 T (OMZ 661), Actinomyces oris (OMZ 745), Streptococcus anginosus ATCC 9895 (OMZ 871), T. forsythia (OMZ 1047), P. gingivalis W50 (OMZ 308), P. gingivalis K1A (OMZ $1126)$ and $P$. gingivalis E8 (OMZ 1127). The latter two are genetically modified strains of $P$. gingivalis W50, with a deletion of Lysine-gingipain ( $k g p)$ and Argininegingipain $(\operatorname{rgpArgpB})$ genes, respectively [22]. Each of the biofilm groups in this experimental design contains one of the three $P$. gingivalis strains and all other 9 species. For biofilm formation, $200 \mu \mathrm{l}$ of bacterial cell suspension, containing equal volumes and densities $\left(\mathrm{OD}_{550}=1.0\right)$ of each strain were added onto pelliclecoated hydroxyapatite discs (diameter $5 \mathrm{~mm}$ ), in $1.6 \mathrm{ml}$ growth medium supplemented with $0.5 \%$ hemin, as described earlier [53]. The medium was renewed after $16 \mathrm{~h}$ and $24 \mathrm{~h}$, during the total incubation time of $64 \mathrm{~h}$. The discs were dip-washed three-times daily.

\section{Biofilm harvesting}

After $64 \mathrm{~h}$ of incubation, the biofilm discs were ready to be harvested. For quantification of the bacterial numbers in the biofilm, the discs were vigorously vortexed for $2 \mathrm{~min}$ in $0.9 \% \mathrm{NaCl}$ and then sonicated at $25 \mathrm{~W}$ in a Sonifier B-12 (Branson Sonic Power Company) for $5 \mathrm{sec}$. For confocal laser scanning microscopy (CLSM) of the biofilm structure, the discs were dip-washed and immediately fixed in 4\% paraformaldehyde (Merck, Darmstadt, Germany) at $4^{\circ} \mathrm{C}$ for $1 \mathrm{~h}$ before being processed for fluorescence 
in situ hybridization (FISH) or immunofluorescence (IF) analysis.

\section{Quantification of bacteria by FISH and IF}

The bacterial suspensions were diluted, fixed on the slides, stained and counted as described [54,55]. For FISH staining, slides were fixed at $4^{\circ} \mathrm{C}$ with $4 \%$ paraformaldehyde in PBS for 20 min and for IF staining they were fixed at room temperature with methanol for $2 \mathrm{~min}$, before they were incubated with the antibodies at $37^{\circ} \mathrm{C}$. FISH was used for the evaluation of S. oralis, S. anginosus and V. dispar (oligonucleotide probes listed in Table 1), while IF was used for the evaluation of $T$. denticola, $C$. rectus, T. forsythia, $P$. gingivalis, $P$. intermedia, $F$. nucleatum and A. oris (antibodies listed in Table 2).

For FISH, the fixed samples were first pre-hybridized, with hybridization buffer containing $0.9 \mathrm{M} \mathrm{NaCl}, 20 \mathrm{mM}$ Tris/ $\mathrm{HCl}(\mathrm{pH} 7.5), 0.01 \% \mathrm{SDS}$, formamide (as indicated in Table 1) at $46^{\circ} \mathrm{C}$, for $15 \mathrm{~min}$. Following this step, hybridization was performed using specific oligonucleotide probes (Table 1 ) at the same temperature, for $3 \mathrm{~h}$. Thereafter, the samples were incubated at $48^{\circ} \mathrm{C}$ with pre-warmed wash buffer containing $20 \mathrm{mM}$ Tris $/ \mathrm{HCl}$ (pH7.5), $5 \mathrm{mM}$ EDTA, $0.01 \% \mathrm{SDS}$, and $40-159 \mathrm{mM} \mathrm{NaCl}$ for $30 \mathrm{~min}$. For CLSM and image analysis, the samples were counterstained with a mixture of $3 \mu \mathrm{M}$ YoPro-1 iodide (Invitrogen, Basel, Switzerland) and $15 \mu \mathrm{M}$ Sytox Green (Invitrogen, Basel, Switzerland) then embedded with $10 \mu \mathrm{l}$ Mowiol [55] with the biofilm surface facing towards the chamber slides. Prior to qualification, the samples were coated with mounting buffer consisting of $90 \%$ ultrapure glycerol and $10 \% 25 \mathrm{mg} / \mathrm{g}$ DABCO (Sigma-Aldrich, Buchs, Switzerland), on 24 well slides, Finally, the stained bacterial cells were visualized under an Olympus BX60 fluorescence microscope (Olympus Optical AG, Volketswil, Switzerland), at 100× magnification.

The box-plot data presented derives from four independent experiments each performed in triplicate biofilm cultures. The values were logarithmically transformed, and then inserted to Prism v.6 software (GraphPad, La Jolla California USA). The statistical differences between the groups were calculated by one-way ANOVA, using the Tukey's post-hoc test for multiple comparisons $(P \leq 0.01)$.

\section{Confocal laser scanning microscopy and image analysis}

For evaluation of the biofilm structure, CLSM was used for each one of the four independent experiments. The

Table 1 16S rRNA oligonucleotide probes for FISH

\begin{tabular}{lllll}
\hline Target & Probe name & FA & Sequence $\left(\mathbf{5}^{\prime} \rightarrow \mathbf{3}^{\prime}\right)$ & Ref. \\
\hline V. dispar & VEI217 & $45 \%$ & AATCCCCTCCTTCAGTGA & {$[55]$} \\
S. oralis & MIT447 & $25 \%$ & CACYCGTTCTTCTCTTACA & {$[56]$} \\
S. anginosus & Sang1203 & $45 \%$ & GGTACACCTTCACCACAC & {$[57]$} \\
\hline
\end{tabular}

$\mathrm{FA}$; Formamide concentration in the hybridization buffer.
Table 2 Antibodies for IF

\begin{tabular}{llll}
\hline Target & Antibody name & Isotype & Ref. \\
\hline C. rectus & $212 \mathrm{WR} 2$ & mouse lgG3 & {$[58]$} \\
T. forsythia & $103 \mathrm{BF} 1.1$ & mouse lgG2b & {$[59]$} \\
P. gingivalis & $61 \mathrm{BG} 1.3$ & mouse lgG1 & {$[60]$} \\
P. intermedia & $37 \mathrm{Bl6} .1$ & rat lgG2b & {$[53]$} \\
F. nucleatum & $305 \mathrm{FN} 1.2$ & mouse lgM & {$[61]$} \\
A. oris & 396AN1 & mouse lgM & {$[61]$} \\
T. denticola & CD-1 & Rabbit polyclonal antiserum & {$[41]$} \\
\hline
\end{tabular}

biofilm-containing discs stained by FISH or IF were visualized using a Leica SP-5 microscope at the Center of Microscopy and Image Analysis of the University of Zürich (ZMB), with a resonant scanner system $(8000 \mathrm{~Hz})$, a diode laser (405 nm excitation), an argon laser (458 nm/ $476 \mathrm{~nm} / 488 \mathrm{~nm} / 496 \mathrm{~nm} / 514 \mathrm{~nm}$ excitation) and a helium neon laser $(561 \mathrm{~nm} / 594 \mathrm{~nm} / 633 \mathrm{~nm}$ excitation). Filters were set to $500-540 \mathrm{~nm}, 570-630 \mathrm{~nm}$, and $660-710$ for detection of YoPro-1 iodide \& Sytox Green mixture, Cy3 and $\mathrm{Cy} 5$, respectively. All images were captured using a $63 \times$ objective (glycerol immersion, NA 1.3). Stacked images were further processed using the Imaris ${ }^{\text {TM }}$ 7.4.0 software (Bitplane, Zürich, Switzerland), in order to virtually reconstruct the biofilm structure.

\section{Competing interests}

The authors declare that they have no competing interests.

\section{Authors' contribution}

NB and GNB conceived the study. BK, GNB, TT, JAO, MAC and NB designed the study. JAO and MAC generated and provided the Porphyromonas gingivalis gingipain mutants. BK performed the experiments. BK and NB performed the data analysis. BK, GNB and NB wrote the paper. T, JAO and $M A C$ reviewed and approved the final version of the paper. All authors read and approved the final manuscript.

\section{Acknowledgements}

We thank the Centre of Microscopy and Image Analysis (ZMB) of the University of Zürich for their support with confocal microscopy. This study was supported by the authors' Institutes, the Forschungskredit Grant of the University of Zürich (NB), and the Medical Research Council UK grant MR/J011118/1 (MAC).

\section{Author details}

${ }^{1}$ Oral Translational Research, Institute of Oral Biology, Center of Dental Medicine, University of Zürich, Plattenstrasse 11, 8032 Zürich, Switzerland.

${ }^{2}$ Oral Microbiology and Immunology, Institute of Oral Biology, Center of Dental Medicine, University of Zürich, Plattenstrasse 11, 8032 Zürich, Switzerland. ${ }^{3}$ Barts and The London Institute of Dentistry, Queen Mary University of London, London E1 2 AD, UK.

Received: 24 June 2014 Accepted: 26 September 2014 Published online: 02 October 2014

\section{References}

1. Socransky SS, Haffajee AD: Periodontal microbial ecology. Periodontol 2000 2005, 38:135-187.

2. Darveau RP: Periodontitis: a polymicrobial disruption of host homeostasis. Nat Rev Microbiol 2010, 8(7):481-490.

3. Aas JA, Paster BJ, Stokes LN, Olsen I, Dewhirst FE: Defining the normal bacterial flora of the oral cavity. J Clin Microbiol 2005, 43(11):5721-5732. 
4. Hajishengallis G, Lamont RJ: Beyond the red complex and into more complexity: the polymicrobial synergy and dysbiosis (PSD) model of periodontal disease etiology. Mol Oral Microbiol 2012, 27(6):409-419.

5. Paster BJ, Boches SK, Galvin JL, Ericson RE, Lau CN, Levanos VA, Sahasrabudhe A, Dewhirst FE: Bacterial diversity in human subgingival plaque. J Bacteriol 2001, 183(12):3770-3783.

6. Socransky SS, Haffajee AD, Cugini MA, Smith C, Kent RL Jr: Microbial complexes in subgingival plaque. J Clin Periodontol 1998, 25(2):134-144.

7. Hajishengallis G: Immune evasion strategies of Porphyromonas gingivalis. J Oral Biosci 2011, 53(3):233-240.

8. Hajishengallis G, Darveau RP, Curtis MA: The keystone-pathogen hypothesis. Nat Rev Microbiol 2012, 10(10):717-725.

9. Bostanci N, Belibasakis GN: Porphyromonas gingivalis: an invasive and evasive opportunistic oral pathogen. FEMS Microbiol Lett 2012, 333(1):1-9.

10. Curtis MA, Aduse-Opoku J, Rangarajan M: Cysteine proteases of Porphyromonas gingivalis. Crit Rev Oral Biol Med 2001, 12(3):192-216.

11. O'Brien-Simpson NM, Black CL, Bhogal PS, Cleal SM, Slakeski N, Higgins TJ, Reynolds EC: Serum immunoglobulin G (IgG) and IgG subclass responses to the RgpA-Kgp proteinase-adhesin complex of Porphyromonas gingivalis in adult periodontitis. Infect Immun 2000, 68(5):2704-2712.

12. Gibson FC 3rd, Savelli J, Van Dyke TE, Genco CA: Gingipain-specific IgG in the sera of patients with periodontal disease is necessary for opsonophagocytosis of Porphyromonas gingivalis. J Periodonto/ 2005 76(10):1629-1636

13. Milner P, Batten JE, Curtis MA: Development of a simple chemically defined medium for Porphyromonas gingivalis: requirement for alpha-ketoglutarate. FEMS Microbiol Lett 1996, 140(2-3):125-130.

14. Sroka A, Sztukowska M, Potempa J, Travis J, Genco CA: Degradation of host heme proteins by lysine- and arginine-specific cysteine proteinases (gingipains) of Porphyromonas gingivalis. J Bacteriol 2001, 183(19):5609-5616.

15. Bramanti TE, Holt SC: Roles of porphyrins and host iron transport proteins in regulation of growth of Porphyromonas gingivalis W50. J Bacteriol 1991, 173(22):7330-7339

16. Bostanci N, Belibasakis GN: Doxycycline inhibits TREM-1 induction by Porphyromonas gingivalis. FEMS Immunol Med Microbiol 2012, 66(1):37-44

17. Hajishengallis G, Abe T, Maekawa T, Hajishengallis E, Lambris JD: Role of complement in host-microbe homeostasis of the periodontium. Semin Immunol 2013, 25(1):65-72.

18. Hajishengallis G, Lambris JD: Complement and dysbiosis in periodontal disease. Immunobiology 2012, 217(11):1111-1116.

19. Maekawa T, Krauss JL, Abe T, Jotwani R, Triantafilou M, Triantafilou K, Hashim A, Hoch S, Curtis MA, Nussbaum G, Lambris JD, Hajishengallis G: Porphyromonas gingivalis manipulates complement and TLR signaling to uncouple bacterial clearance from inflammation and promote dysbiosis. Cell Host Microbe 2014, 15(6):768-778.

20. Liang S, Krauss JL, Domon H, McIntosh ML, Hosur KB, Qu H, Li F, Tzekou A, Lambris JD, Hajishengallis G: The C5a receptor impairs IL-12-dependent clearance of Porphyromonas gingivalis and is required for induction of periodontal bone loss. J Immunol 2011, 186(2):869-877.

21. Abe T, Hosur KB, Hajishengallis E, Reis ES, Ricklin D, Lambris JD, Hajishengallis G: Local complement-targeted intervention in periodontitis: proof-of-concept using a C5a receptor (CD88) antagonist. J Immunol 2012, 189(11):5442-5448

22. Aduse-Opoku J, Davies NN, Gallagher A, Hashim A, Evans HE, Rangarajan M, Slaney JM, Curtis MA: Generation of lys-gingipain protease activity in Porphyromonas gingivalis W50 is independent of Arg-gingipain protease activities. Microbiology 2000, 146(Pt 8):1933-1940.

23. Fletcher HM, Schenkein HA, Morgan RM, Bailey KA, Berry CR, Macrina FL: Virulence of a Porphyromonas gingivalis W83 mutant defective in the prtH gene. Infect Immun 1995, 63(4):1521-1528.

24. Tokuda M, Karunakaran T, Duncan M, Hamada N, Kuramitsu H: Role of Arg-gingipain A in virulence of Porphyromonas gingivalis. Infect Immun 1998, 66(3):1159-1166

25. Kesavalu L, Holt SC, Ebersole JL: Porphyromonas gingivalis virulence in a murine lesion model: effects of immune alterations. Microb Pathog 1997, 23(6):317-326.

26. O'Brien-Simpson NM, Paolini RA, Hoffmann B, Slakeski N, Dashper SG, Reynolds EC: Role of RgpA, RgpB, and Kgp proteinases in virulence of Porphyromonas gingivalis W50 in a murine lesion model. Infect Immun 2001, 69(12):7527-7534.

27. Hamedi M, Belibasakis GN, Cruchley AT, Rangarajan M, Curtis MA, Bostanci $\mathrm{N}$ : Porphyromonas gingivalis culture supernatants differentially regulate interleukin-1beta and interleukin-18 in human monocytic cells. Cytokine 2009, 45(2):99-104

28. Reddi D, Bostanci N, Hashim A, Aduse-Opoku J, Curtis MA, Hughes FJ, Belibasakis GN: Porphyromonas gingivalis regulates the RANKL-OPG system in bone marrow stromal cells. Microbes Infect 2008, 10(14-15):1459-1468.

29. Reddi D, Brown SJ, Belibasakis GN: Porphyromonas gingivalis induces RANKL in bone marrow stromal cells: involvement of the p38 MAPK. Microb Pathog 2011, 51(6):415-420.

30. Belibasakis GN, Bostanci N, Hashim A, Johansson A, Aduse-Opoku J, Curtis MA, Hughes FJ: Regulation of RANKL and OPG gene expression in human gingival fibroblasts and periodontal ligament cells by Porphyromonas gingivalis: a putative role of the Arg-gingipains. Microb Pathog 2007, 43(1):46-53.

31. Bostanci N, Allaker R, Johansson U, Rangarajan M, Curtis MA, Hughes FJ, McKay IJ: Interleukin-1alpha stimulation in monocytes by periodontal bacteria: antagonistic effects of Porphyromonas gingivalis. Oral Microbiol Immunol 2007, 22(1):52-60.

32. Bostanci N, Emingil G, Afacan B, Han B, Ilgenli T, Atilla G, Hughes FJ, Belibasakis GN: Tumor necrosis factor-alpha-converting enzyme (TACE) levels in periodontal diseases. J Dent Res 2008, 87(3):273-277.

33. Belibasakis GN, Bostanci N, Reddi D: Regulation of protease-activated receptor-2 expression in gingival fibroblasts and Jurkat T cells by Porphyromonas gingivalis. Cell Biol Int 2010, 34(3):287-292.

34. Bostanci N, Thurnheer T, Aduse-Opoku J, Curtis MA, Zinkernagel AS, Belibasakis GN: Porphyromonas gingivalis regulates TREM-1 in human polymorphonuclear neutrophils via its gingipains. PLoS One 2013, 8(10):e75784.

35. Ammann TW, Belibasakis GN, Thurnheer T: Impact of early colonizers on in vitro subgingival biofilm formation. PLoS One 2013, 8(12):e83090.

36. Belibasakis $\mathrm{GN}$, Thurnheer T, Bostanci N: Interleukin-8 responses of multi-layer gingival epithelia to subgingival biofilms: role of the "red complex" species. PLoS One 2013, 8(12):e81581.

37. Belibasakis GN, Guggenheim B, Bostanci N: Down-regulation of NLRP3 inflammasome in gingival fibroblasts by subgingival biofilms: involvement of Porphyromonas gingivalis. Innate Immun 2013, 19(1):3-9.

38. Kolenbrander PE, Palmer RJ Jr, Rickard AH, Jakubovics NS, Chalmers NI, Diaz PI: Bacterial interactions and successions during plaque development. Periodontol 2000 2006, 42:47-79.

39. Schultz-Haudt S, Bruce MA, Bibby BG: Bacterial factors in nonspecific gingivitis. J Dent Res 1954, 33(4):454-458.

40. Macdonald JB, Sutton RM, Knoll ML, Madlener EM, Grainger RM: The pathogenic components of an experimental fusospirochetal infection. J Infect Dis 1956, 98(1):15-20.

41. Belibasakis $G N$, Thurnheer $T$ : Validation of antibiotic efficacy on in vitro subgingival biofilms. J Periodontol 2014, 85(2):343-348.

42. Ammann TW, Gmur R, Thurnheer T: Advancement of the 10-species subgingival Zurich Biofilm model by examining different nutritional conditions and defining the structure of the in vitro biofilms. BMC Microbiol 2012, 12(1):227.

43. Grenier D, Roy S, Chandad F, Plamondon P, Yoshioka M, Nakayama K, Mayrand D: Effect of inactivation of the Arg- and/or Lys-gingipain gene on selected virulence and physiological properties of Porphyromonas gingivalis. Infect Immun 2003, 71(8):4742-4748.

44. Ito R, Ishihara K, Shoji M, Nakayama K, Okuda K: Hemagglutinin/Adhesin domains of Porphyromonas gingivalis play key roles in coaggregation with Treponema denticola. FEMS Immunol Med Microbiol 2010, 60(3):251-260.

45. Abe N, Baba A, Takii R, Nakayama K, Kamaguchi A, Shibata Y, Abiko Y, Okamoto K, Kadowaki T, Yamamoto K: Roles of Arg- and Lys-gingipains in coaggregation of Porphyromonas gingivalis: identification of its responsible molecules in translation products of $\mathrm{rgpA}$, kgp, and hagA genes. Biol Chem 2004, 385(11):1041-1047.

46. Yamada M, Ikegami A, Kuramitsu HK: Synergistic biofilm formation by Treponema denticola and Porphyromonas gingivalis. FEMS Microbiol Lett 2005, 250(2):271-277.

47. Andrian $\mathrm{E}$, Grenier $\mathrm{D}$, Rouabhia M: In vitro models of tissue penetration and destruction by Porphyromonas gingivalis. Infect Immun 2004, 72(8):4689-4698.

48. Hojo K, Nagaoka S, Ohshima T, Maeda N: Bacterial interactions in dental biofilm development. J Dent Res 2009, 88(11):982-990.

49. Kuramitsu HK, Chen W, Ikegami A: Biofilm formation by the periodontopathic bacteria Treponema denticola and Porphyromonas gingivalis. J Periodontol 2005, 76(11 Suppl):2047-2051. 
50. Zhu Y, Dashper SG, Chen YY, Crawford S, Slakeski N, Reynolds EC: Porphyromonas gingivalis and Treponema denticola synergistic polymicrobial biofilm development. PLoS One 2013, 8(8):e71727.

51. Thurnheer T, Belibasakis GN, Bostanci N: Colonization of gingival epithelia by subgingival biofilms in vitro: role of "red complex" bacteria. Arch Oral Biol 2014, 59(9):977-986.

52. Guggenheim B, Gmur R, Galicia JC, Stathopoulou PG, Benakanakere MR, Meier A, Thurnheer T, Kinane DF: In vitro modeling of host-parasite interactions: the 'subgingival' biofilm challenge of primary human epithelial cells. BMC Microbiol 2009, 9:280

53. Gmur R, Guggenheim B: Antigenic heterogeneity of Bacteroides intermedius as recognized by monoclonal antibodies. Infect Immun 1983, 42(2):459-470.

54. Zuger J, Luthi-Schaller H, Gmur R: Uncultivated Tannerella BU045 and BU063 are slim segmented filamentous rods of high prevalence but low abundance in inflammatory disease-associated dental plaques. Microbiology 2007, 153(Pt 11):3809-3816.

55. Thurnheer T, Gmur R, Guggenheim B: Multiplex FISH analysis of a six-species bacterial biofilm. J Microbiol Methods 2004, 56(1):37-47.

56. Thurnheer T, Gmur R, Giertsen E, Guggenheim B: Automated fluorescent in situ hybridization for the specific detection and quantification of oral streptococci in dental plaque. J Microbiol Methods 2001, 44(1):39-47.

57. Ammann TW, Bostanci N, Belibasakis GN, Thurnheer T: Validation of a quantitative real-time PCR assay and comparison with fluorescence microscopy and selective agar plate counting for species-specific quantification of an in vitro subgingival biofilm model. J Periodontal Res 2013, 48(4):517-526.

58. Gmur R: Value of New Serological Probes for the Study of Putative Periodontal Pathogens: A Survey after Five Years of Application. Zurich: Dental Center of the University of Zurich; 1995:86.

59. Werner-Felmayer G, Guggenheim B, Gmur R: Production and characterization of monoclonal antibodies against Bacteroides forsythus and Wolinella recta. J Dent Res 1988, 67(3):548-553.

60. Gmur R, Werner-Felmayer G, Guggenheim B: Production and characterization of monoclonal antibodies specific for Bacteroides gingivalis. Oral Microbiol Immunol 1988, 3(4):181-186.

61. Thurnheer T, Guggenheim B, Gmur R: Characterization of monoclonal antibodies for rapid identification of Actinomyces naeslundii in clinical samples. FEMS Microbiol Lett 1997, 150(2):255-262.

doi:10.1186/s12866-014-0258-7

Cite this article as: Bao et al:: Role of Porphyromonas gingivalis gingipains in multi-species biofilm formation. BMC Microbiology 2014 14:258.

\section{Submit your next manuscript to BioMed Central and take full advantage of:}

- Convenient online submission

- Thorough peer review

- No space constraints or color figure charges

- Immediate publication on acceptance

- Inclusion in PubMed, CAS, Scopus and Google Scholar

- Research which is freely available for redistribution

Submit your manuscript at www.biomedcentral.com/submit
( Biomed Central 